\title{
Regional and environmental impacts of expanding the heavy duty vehicle charge to the secondary road network in Austria
}

\author{
Karl W. Steininger • Christoph Schmid • \\ Alexandra Tobin
}

Published online: 23 February 2012

(C) Springer Science+Business Media New York 2012

\begin{abstract}
In road freight transport a particularly large share of the total social costs generated is not borne by road users. To correct for this, many European countries use pricing instruments specifically targeted at heavy duty vehicles, so far targeted almost exclusively at the primary road network. In line with the overall EU objective of greening the transport sector, we discuss the possibility of expanding the road charging system to a more comprehensive, area-wide one. The degree to which peripheral or disadvantaged regions are hit over-proportionally by such a measure remains an open question in the literature on heavy duty vehicle road pricing. We combine an inputoutput and a computable general equilibrium approach to analyse the case for Austria. We find that while it is not the sectors of highest economic importance in the periphery regions that are hit by the charge, those sectors that are hit are those which are relatively more important in peripheral regions (with up to a twofold share in value added) and for whom production price impacts tend to be relatively strong. The short term consumer price effect of extending the current primary road network charges to the secondary network is found not to exceed $0.15 \%$. In terms of the principles of sustainable transport we find that extending charge coverage is compatible with most core principles, the exception being the principle of regional need. In terms of environmental impact, for example, expanding heavy duty vehicle charges to the secondary road network reduces heavy duty vehicle kilometres in the overall network (and related emissions) by roughly $2 \%$. However, in order to comply with the needs principle, suitable complementary transfer policies need to be designed and implemented for peripheral regions.
\end{abstract}

K. W. Steininger · C. Schmid · A. Tobin

Wegener Center for Climate and Global Change, University of Graz, Leechgasse 25,

8010 Graz, Austria

K. W. Steininger $(\bowtie)$

Department of Economics, University of Graz, Universitaetsstr. 15, 8010 Graz, Austria

e-mail: karl.steininger@uni-graz.at 
Keywords Freight transport pricing - Environmental taxes ·

Transport and environment - Sustainable freight transport - Regional development . EU greening transport package

\section{JEL Classification C68 $\cdot$ Q $52 \cdot$ R48}

\section{Introduction}

Economists believe that in particular situations, there are clear advantages of using pricing as an instrument in environmental policy. For example, it may allow for improved flexibility across a heterogeneous group of polluters and thus ensure greater cost-efficiency compared to other environmental instruments, e.g. standards (Muller and Sterner 2006). Pricing policy also acts as a continuous incentive since attempts by producers to minimize environmental charges encourage innovation and stimulate environmental improvements (Perman et al. 2011). The use of pricing also has a further feedback effect in that it promotes the development of spatial structures generating lower transport volumes (Grazi and van den Bergh 2008). This is due to the fact that the location decision of firms and households is also (partly) determined by expected transport costs, thus higher transport costs will tend to promote low-distance clustering of activities.

The impact of transport pricing policies depends in practice on the type of charging basis chosen. Greene (2011) finds an (energy) indexed roadway user toll for the US to be acceptable in terms of its environmental effectiveness. Johnson (2005) analyzes a distance-related heavy duty vehicle charge to cover road maintenance for Sweden and finds that the impact is felt more in terms of a trucking reduction than in a shift to less damaging vehicles. Replogle (2008) surveys the worldwide implementations of congestion pricing (higher rates at peak hours) and quantifies their environmental merits in the US, European and Asian cities. In order to detail environmental impact complementary technical analysis is also necessary (Hao et al. 2010). The connections between road freight transport policy and long term environmental objectives is covered by Takeshita (2011) for the global level; or Yang et al. (2009) for California; and Kratena and Meyer (2011) for Austria.

In Europe, kilometre based charges for heavy duty vehicles are already widely used for freight transport. For the EU, for example, the directive on road use charges for heavy goods vehicles ("Eurovignette"), was revised in 2011 to incorporate an environmental cost component, aiming "at reducing pollution from road freight transport and making traffic flow smoother by levying tolls that factor in the cost of air and noise pollution due to traffic (so-called external costs) and help avoid road congestion. To this end, member states may apply an 'external cost charge' on lorries, complementing the already existing infrastructure charge designed to recover the costs of construction, operation, maintenance and development of road infrastructure" (European Council 2011).

However, charges for heavy duty vehicles are currently implemented almost exclusively on the primary road network. Only Switzerland has a more comprehensive charging system, albeit one whose introduction went hand in hand with a 
significant increase in maximum loads (Balmer 2006). So far, no other European country has expanded its heavy duty vehicle charge to cover the secondary road network.

To prevent drivers re-routing to the secondary road network, bans for heavy duty vehicle transport have been implemented at sections particularly exposed to such risk. Yet, as the heavy duty vehicle charge is a comparatively popular instrument, and as freight charges cover only a relatively small share of the costs caused on the secondary road network, comprehensive expansion of the heavy duty vehicle charge has become a crucial political issue in many countries (e.g. in France, Spain, Slovenia, the Czech Republic and Austria).

Informed policy discussion requires clarification of a number of questions:

- Would the impact on heavy duty vehicle mileage and thus on emissions be of any significance at all, given that road transport on the secondary network could be rather price-insensitive?

- Which economic sectors would be particularly hit in economic terms?

- Are there any significant macroeconomic impacts to be expected?

- As peripheral regions are proportionally more dependent on the secondary road network, how much more significant are sectoral or overall economic impacts in these regions?

In answering these questions, we follow the following sustainable development principles for transport derived by Gudmundsson and Höjer (1996). These are: preserving natural resources and the option value of natural and man-made capital for future generations, improving quality of life for individuals, and ensuring a fair distribution of life-quality. Analysing the policy impact on emissions, particularly on greenhouse gas emissions, shows the extent to which the first principle is supported. Analysing policy impact in economic and social terms covers the second principle, and analysing the impact on regional distribution covers the third.

Changes in transport pricing, especially when chosen at significant levels, require careful impact analysis. In terms of sustainability impact assessment, the European Union (EU), for example, asks for "careful assessment of the full effects of a policy proposal [that] must include estimates of economic, environmental and social impacts" (EC 2001). As set out in Böhringer and Löschel (2006) in some detail, the quantification of trade-offs in such an impact assessment analysis calls for the use of numerical techniques. One of these approaches, CGE modelling, "can incorporate several key sustainability (meta-)indicators in a single micro-consistent framework, thereby allowing for a systematic quantitative trade-off analysis between environmental quality, economic performance and income distribution" (Böhringer and Löschel 2006: 50-51).

Here we first use the precursor of CGE analysis, input-output-analysis, in order to obtain an upper limit for (sectoral and overall) price impacts. Input-output analysis does not account for substitution effects and thus actual price increase is overestimated.

Ultimately, however, we are interested in a quantitative evaluation of the sustainability impacts with respect to nationwide expansion of the heavy duty 
vehicle charge, and thus develop a nationwide CGE model to analyse those impacts here. We use micro-based charge adjusted vehicle kilometres by sector and type of road network, and use vehicle charge adjusted freight transport prices to derive the implicit charge on freight transport tonne-kilometres, differentiated by sector. This implicit charge per monetary unit of value added rises with the sector's share of intermediate inputs transported on the secondary road network, with transport intensity of value added, and with the decline in substitution options.

For the analysis of fairness in regional distribution we use a regionally differentiated analysis of economic activities and related transport flows to quantify the impacts for a representative peripheral region, the Waldviertel. This serves to point out the degree of regional imbalance in the effects of such an instrument. The fairness aspect was made operational by Törnblorn and Foa (1983) and was used in environmental transport policy by Hammar and Jagers (2007) who employed the three principles of equality, need and equity. Equality implies equal burdens across regions, need implies that those regions in stronger need of freight transport (emissions) should reduce (them) less, and equity reflects the polluter pays principle, i.e. those regions which contribute most emissions should reduce most. Condeco-Melhorado et al. (2011) show the accessibility effects of area-wide implementation of heavy duty vehicle pricing in Spain. They find that it is "detrimental to the regions that already had a poorer level of accessibility, and increases the accessibility differences of the different regions while reducing territorial equity." We complement their analysis by providing a quantification of economic implications for peripheral regions.

The issue we focus on here, the expansion of an existing heavy duty vehicle charge to cover the secondary road network, is of little relevance for transit transport and only of minor relevance for export and import transport, as it relates primarily to internal transport (i.e. where both origin and destination lie within a country). Thus, foreign trade aspects are of little relevance here. Foreign trade induced impacts are of significant relevance, however, when a heavy duty vehicle charge is initially introduced in a country (see Veen-Groot and Nijkamp 1999; Steininger 2002).

This article is structured as follows. Section 2 presents three scenarios for the expansion of the heavy duty vehicle charge, specifies the modelling framework for analysis, and focuses on national macroeconomic analysis within the CGE framework to account for all feedback effects. In Sect. 3 these results are complemented by a short term input-output analysis of price impacts. Section 4 analyses regional differentiation of impacts and Sect. 5 discusses overall results. A final section summarizes the main conclusions.

\section{Nationwide implications of a heavy duty vehicle charge expansion}

\subsection{Scenarios}

Let us define the following three rate scenarios: 
(A) Expansion of the current heavy duty vehicle charge $(0.22 € / \mathrm{km}$ on average across heavy duty vehicle classes) from the primary road network to the secondary road network (same rate)

(B) Network coverage as in (A) above, but with a doubling of the rate in the whole network (primary and secondary)

(C) Expansion of the heavy duty vehicle charge to cover the secondary network, but at only half the rate prevailing on the primary road network.

For each rate scenario we use the results of a detailed transport reaction analysis by freight good category (NSTR, Nomenclature uniforme des marchandises pour les Statistiques de Transport, Revisée), including optimization of vehicle load factors, route optimization, and substitution by foreign transport routes as carried out in Herry et al. (2008) (see Sect. 2.1.1 below for details). The results on vehiclekilometres and tonne-kilometres are given for the nationwide aggregate in Table 1.

A price increase of $24 \%$ (scenario A) in the secondary road network thus reduces related vehicle-kilometres by $3.5 \%$, and overall by $1.9 \%$. An increase in vehiclecost per km (scenario B) of both $20 \%$ for the primary and $49 \%$ for the secondary road network reduces overall vehicle-kilometres by a significantly higher figure of $9.1 \%$.

\subsubsection{Overview of transport reaction analysis by Herry et al. (2008)}

Using an initial cost of $€ 0.9$ per vehicle-kilometre (net of road charges), Herry et al. (2008) identify five reactions to each of the above rate scenarios. These add up to the total reaction as given in Table 1 . We thus have:

- Route change to foreign territory (for transit and-to a much lower degreeexport/import transport): Herry Consult and Snizek (2002) estimate price elasticity here to be -0.2 for time-critical transport (five out of fourteen goods categories are considered as such) and -0.78 for non-time-critical transport. For export/import transport these elasticities are reduced by $90 \%$ in Herry et al. (2008).

Table 1 Transport reaction to nationwide expansion of heavy duty vehicle charge

\begin{tabular}{|c|c|c|c|c|c|c|c|c|}
\hline \multirow[t]{2}{*}{$\begin{array}{l}\text { Rate- } \\
\text { scenario }\end{array}$} & \multicolumn{3}{|c|}{ Vehicle-kilometres } & \multicolumn{3}{|c|}{ Tonne-kilometres } & \multicolumn{2}{|c|}{$\begin{array}{l}\text { Unit price per vehicle- } \\
\text { kilometre }\end{array}$} \\
\hline & Total & $\begin{array}{l}\text { Primary } \\
\text { road } \\
\text { network }\end{array}$ & $\begin{array}{l}\text { Secondary } \\
\text { road } \\
\text { network }\end{array}$ & Total & $\begin{array}{l}\text { Primary } \\
\text { road } \\
\text { network }\end{array}$ & $\begin{array}{l}\text { Secondary } \\
\text { road } \\
\text { network }\end{array}$ & $\begin{array}{l}\text { Primary } \\
\text { road } \\
\text { network }\end{array}$ & $\begin{array}{l}\text { Secondary } \\
\text { road } \\
\text { network }\end{array}$ \\
\hline & \multicolumn{8}{|c|}{ Change in $\%$} \\
\hline A & -1.9 & -1.0 & -3.5 & -1.0 & -0.4 & -2.6 & 0.0 & 24.4 \\
\hline B & -9.1 & -9.2 & -8.9 & -6.5 & -6.7 & -6.0 & 19.6 & 48.9 \\
\hline $\mathrm{C}$ & -0.9 & -0.5 & -1.7 & -0.5 & -0.2 & -1.3 & 0.0 & 12.2 \\
\hline
\end{tabular}

Source: Herry et al. (2008) 
- Modal-split change: Based on Herry Consult (2004) the cross-price elasticity of a shift to rail transport of between 0.11 (agricultural goods, wood, textiles), 0.16 (cement, glass, ceramics) and 0.28 (all other goods) is used for long-distance transport, and is reduced by $20 \%$ for short-distance transport.

- Load optimization: Freight carriers react by optimising loads and reducing the number of empty trips. Based on ICIPE and Herry (2001) elasticities capturing the reaction of vehicle-km to price changes are taken separately for each of the 14 goods categories, and vary from between -0.01 (solid mineral fuels) to -0.19 (textiles, vehicles, special transport goods).

- Route optimization: Based on information on the share of electronic route optimization equipment and on interviews with practitioners a lower end reduction potential of $2 \%$ is used.

- Finally, domestic route change. After the initial introduction of the heavy duty vehicle charge on the primary road network in Austria a shift to the secondary road network (captured by an elasticity figure of 0.8 ) was observed. Prohibitions on the use of specific routes have since led to a decline in detour traffic. To cover the shift in the reverse direction, the corresponding elasticity figure was halved.

\subsection{National CGE model and transport scenario modeling}

For the quantification of economic implications at the national level we use the transport oriented comparative static small open economy CGE model developed in Steininger (2002), expand it to distinguish 37 production sectors, and introduce nonmarket clearing in the labour market such that capturing the impact of transport pricing on employment becomes possible. The type of unemployment modelled is that caused by a rigid minimum wage (i.e. classical unemployment). The nationwide introduction of the kilometre-based heavy duty vehicle charge as well as the required investments for the kilometre-based charge system affect domestic production directly (e.g. through decreased demand from sectors reducing their output, together with additional demand, e.g. for labour in the charging-system, data-handling sector etc.) and indirectly (e.g. through decreased demand from intermediate inputs to the former sectors, together with additional demand e.g. for labour for the production of data-handling devices). Given the assumption of classical unemployment the resulting shift in the demand function for labour does not immediately affect the price of the production factor but rather leads to an increase (or decrease) in the amount of labour employed. As in Steininger (2002) the labour market is specified as follows.

$$
w \geq \overline{w_{l o w}} \perp u
$$

with $w$ denoting the real wage rate, $\overline{w_{l o w}}$, a lower bound on the real wage rate, and $u$, a rationing factor governing unemployment. In general, if this restriction is binding, i.e., if the market clearing wage is below $\overline{w_{l o w}}$, the rationing factor $\mathrm{u}$ works to adjust labour supply to labour demand. The rationing factor $u$ can be interpreted as unemployment rate, with its level determined endogenously, depending on labour demand and the exogenous variables of labour supply and lower bound real wage 
rate. The lower bound on the wage rate is calculated in model calibration to result in the unemployment rate observed in the base year. Potential labour demand shifts originating from a heavy duty vehicle charge are thus reflected in a change of the unemployment rate.

The heavy duty vehicle charge scenarios described above operate as follows. Cost increases in intermediate input goods resulting from the introduction of the nationwide heavy duty vehicle charge differ across sectors, depending on the respective transportation expenses incurred. To quantify the cost changes per input commodity, in the simulation scenarios we employ the following data: driving performance (in veh-km), transport performance (in tkm) and the corresponding costs (per $\mathrm{km}$ and tkm respectively).

Driving performance (per vehicle) and transport performance (per commodity transported and vehicle used) are adopted from Friedl and Steininger (2002). The average costs per $\mathrm{km}$ and type of vehicle are derived from two earlier studies (Herry 2001 and Due Torri 2007), with the latter being based on interviews with transport companies. The average costs per tkm depend on the average kilometre costs of the heavy duty vehicle used, on the commodity transported, and on the respective average load factors for each commodity group.

In the counterfactuals we shock the economy in the base year (comparative static analysis, implicitly assuming that the policy had been introduced sufficiently early to ensure equilibrium in the base year again). The introduction of the nationwide kilometre-based heavy duty vehicle charge leads to a cost increase per vehiclekilometre driven. The new transport expenses are calculated for each commodity group, based on the driving performance (veh-km) and transport performance (tkm) in the base year. This cost increase leads to a change in driving performance and transport performance patterns (e.g. higher load factors, fewer empty runs) (see Table 1), which finally constitute the final transport costs per tonne-kilometre and commodity group. Knowing the demand for intermediate commodities for each production sector in the reference case, it is then possible to calculate the percentage cost increase for intermediate commodities that the nationwide expansion of the heavy duty vehicle charge implies. By introducing this cost increase as a new intermediate input tax differentiated by sector we are able to model the new policy.

Note: we do not directly model different transport modes or their substitution in the CGE model. We focus rather on the indirect link of the transport reaction model (as set forward in Sect. 2.1.1), the results of which are used to generate the production cost increases by sector, which are then implemented as sectoral output tax increases in the CGE framework. For the public sector the two models are consistent, as the increased cost in the former exactly translates to an increased tax revenue in the latter. To avoid what is seen as unnecessary complexity, price changes in the macro-model are not fed back into the transport reaction model. As we will see below, the macro-induced price changes found are relatively minor, and are thus unlikely to induce any significant impact on the transport reaction model.

In terms of elasticities of substitution (see Reinert and Roland-Holst 1992), it is mainly those on the demand side that are relevant. For estimating final demand a linear expenditure system is employed, whereby expenditure shares are held constant, and intermediate demand is governed by Leontief production functions. 
$\mathrm{CO}_{2}$ emissions are calculated using unit emissions by kilometre and vehicle class.

\subsection{Nationwide implications}

On employing the CGE model as presented in Sect. 2.2 to analyse the introduction of a nationwide heavy duty vehicle charge, we find that at the aggregate level, the impact on value added and employment is crucially dependent on (a) the charge scenario, and on (b) revenue use option chosen. We therefore need to specify use options for the new charge revenues. Under the main option for revenue use we deduct system costs and use half of the remaining amount for infrastructure maintenance of the secondary road network and the rest for a general reduction of the tax burden. We also test for the two other extremes, i.e. of using the revenues after system costs either solely for maintenance, or solely for general tax reduction. The government budget closure ensures that public budget effects due to the policy and revenue use net out. Here, maintenance investment refers to within period expenditure in the construction sector.

The use of revenues for maintenance (in different shares across the scenarios) is chosen with an eye on raising public acceptance of such a heavy duty vehicle charge extension. The secondary road network in Austria is in rather bad shape in many locations. The primary road network, the responsibility of the federal public road authority, is well maintained, and is financed by related network charges. The earmarking of revenue gained from an extension of the charging system to the secondary network to cover related maintenance costs is thus likely to be a political prerequisite for the introduction of such a policy. Modelling the alternative use of revenue for tax reductions follows the double dividend literature (e.g. Bovenberg, 1999) which identifies the optimal way of recycling to be in reducing the (most) distorting pre-existing taxes.

As Fig. 1 shows, the higher the share of revenues used for general tax reduction (which also implies a labour tax reduction), the more positive are the impacts on GDP and employment. The latter impact is due to the decline in the user cost of labour triggered by labour tax reduction in a labour market characterized by excessively high and sticky wages. Thus, formerly unemployed labour becomes employed when labour taxes decline, raising both employment and value added.

In Table 2 the GDP impact and its sensitivity to revenue use is also given for the remaining rate scenarios. We find under rate scenario $B$ that even for a significant reduction in vehicle-kilometres (9\%) and emissions, the GDP impact is small. On the basis of the Austrian environmental balance of transport (Herry et al. 2001), Table 2 also gives the absolute change in external costs by category that is triggered by each road pricing expansion scenario. The 30 million euro reduction in external costs in rate scenario B represents a reduction in total external costs from heavy duty vehicles in Austria of 1.5\% (Herry et al. 2001), which—in terms of GDP-is equivalent to 0.1 per mill.

Impacts differ substantially across economic sectors. In terms of reduced production level and increased production cost, the most strongly hit sector is Stone and Glass Products, Mining (see Fig. 2). 

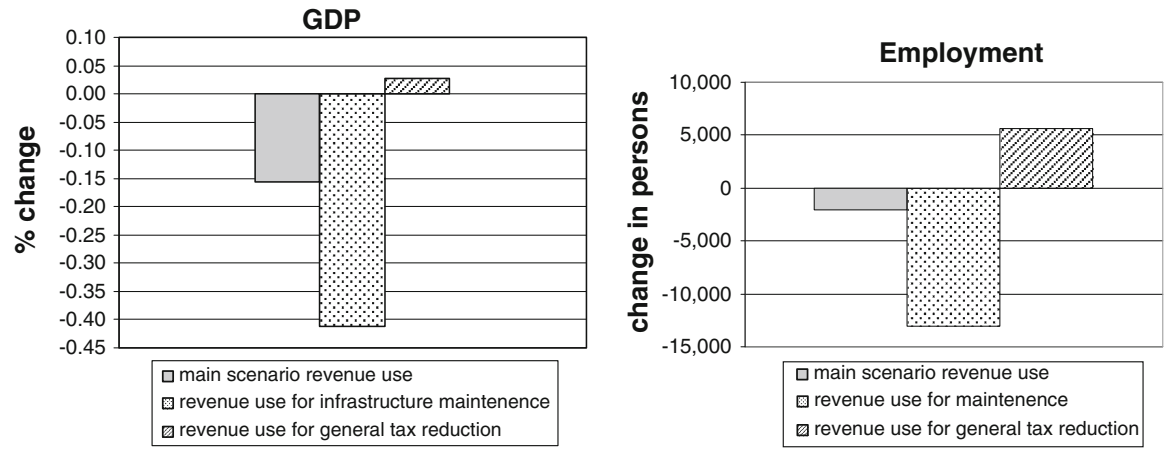

Fig. 1 Macroeconomic impacts of heavy duty vehicle charge scenario A under different revenue use options

Table 2 Macroeconomic and environmental impacts of heavy duty vehicle charge expansion to secondary road network, values in $2006 €$

\begin{tabular}{llll}
\hline & \multicolumn{2}{l}{ Rate scenario } & \\
\cline { 2 - 3 } & A & B & C \\
\hline GDP & (\% Change) & & \\
Sensitivity & -0.16 & -0.48 & -0.07 \\
$\quad$ Revenue use for maintenance only & & & \\
$\quad$ Revenue use for general tax reduction only & -0.41 & -1.32 & -0.21 \\
External costs & 0.03 & 0.42 & -0.02 \\
Climate costs & $($ Change in $€ \mathrm{~m})$ & & \\
Air pollutants & -0.6 & -3.9 & -0.3 \\
Accidents & -2.6 & -17.6 & -1.3 \\
Total & -2.9 & -9.3 & -1.5 \\
\hline
\end{tabular}

External costs based on per vehicle-km external costs in Herry et al. (2001)

In terms of social distribution the production price increase in Stone and Glass Products, Mining implies higher construction costs in housing, ultimately being passed on to consumers, even in the form of higher rents. As the poor spend a significantly higher share of their income on housing (the share of income spent on housing declines continuously from a high $32 \%$ for the lowest two income deciles to only $21 \%$ for the two richest deciles; Statistik Austria 2002). While most other goods expenditure shares are stable across income categories, the main complementary figure to a decline in housing costs when going up the income ladder is expenses on transport (passenger transport in this case), rising from $8 \%$ for the lowest deciles to $18 \%$ for the highest ones. While the price increase appears to hit the poor disproportionally, the impact of the overall housing price increase remains relatively small. Beyond, other effects, especially changes in unemployment (and these strongly depend on the revenue use option chosen), may be more significant in terms of distributional impact. 


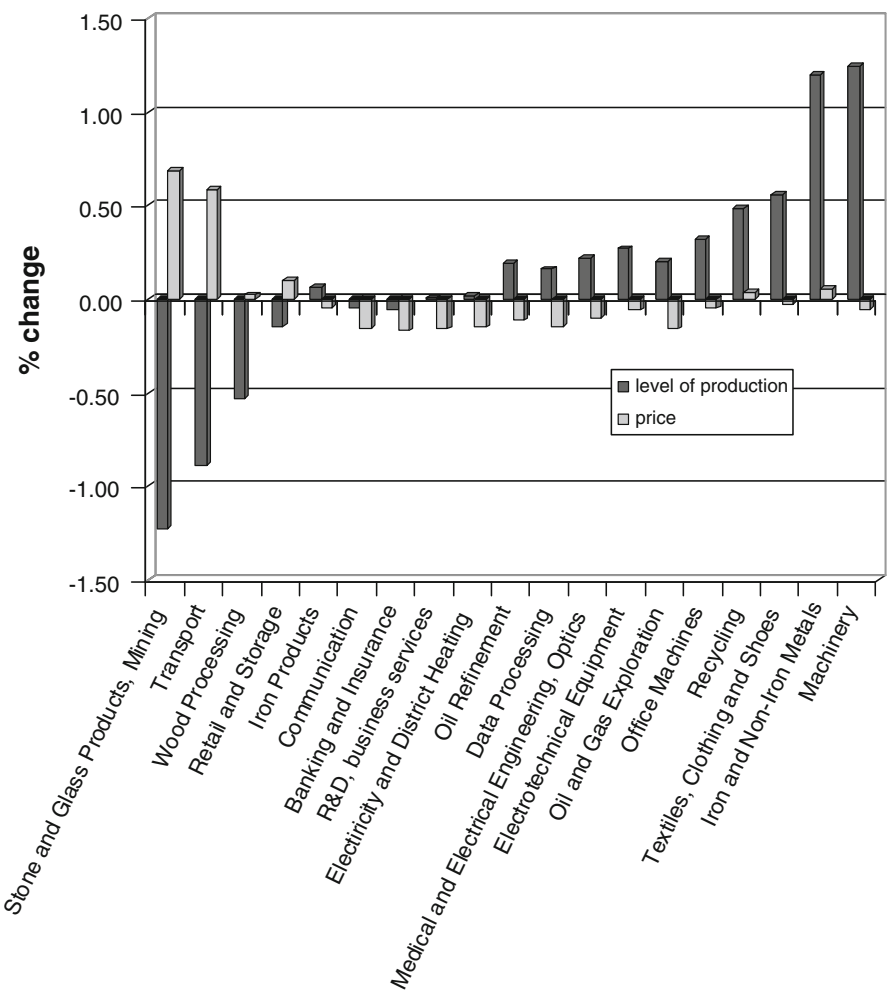

Fig. 2 Output and price changes by sector, rate scenario A, selection of sectors with strongest impact

In terms of environmental effect, a reduction of $1 \%$ of tonne-kilometres in road freight transport under rate scenario A translates into almost double the reduction in terms of vehicle kilometres (i.e. 1.9\%). Greenhouse gas emissions as well as local pollutants from heavy duty vehicle transport decline correspondingly. For rate scenario B (doubling of the charge on both the primary and secondary road network), vehicle kilometres (and emissions) decline by $9 \%$, for rate scenario $\mathrm{C}$ (only half the current primary road network rate is introduced for the secondary road network) the decline is $0.9 \%$.

\section{Short term effects and their upper bounds: input-output analysis}

While the CGE analysis takes counterbalancing impacts into account, e.g. the possibility of labour cost reductions compensating for transport increases, over the short term, some of these counterbalancing effects may not be generated at all, or at least may not be fully generated. Therefore, to establish an upper bound on consumer price impacts for the short run, we employ a straight input-output analysis for price changes. We use absolute additional freight transport expenses for 


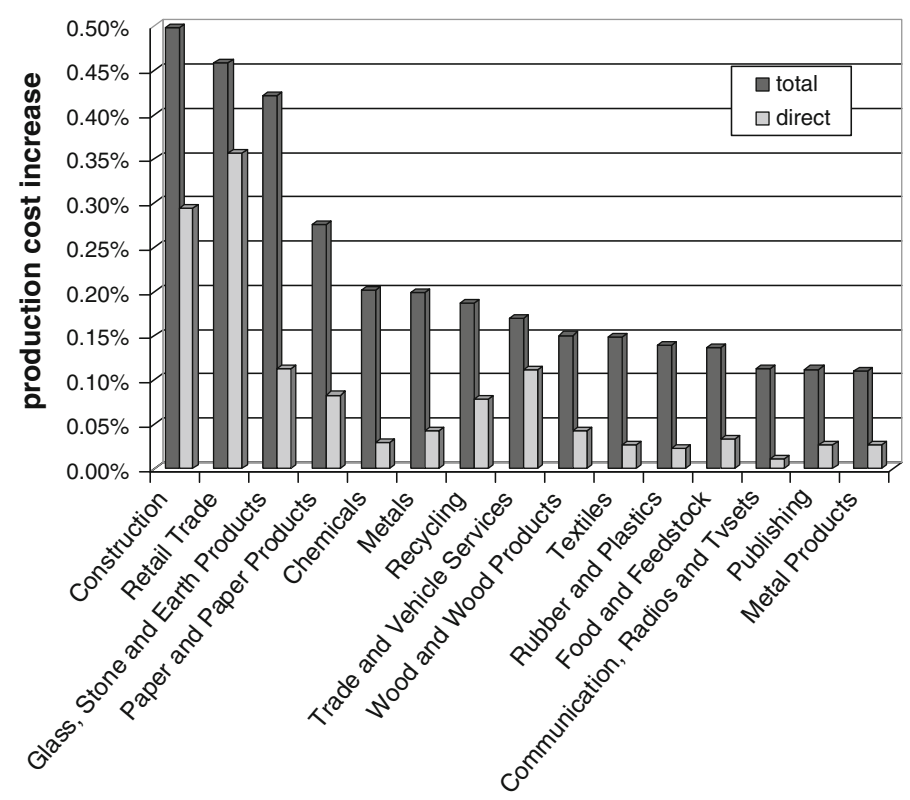

Fig. 3 Production cost increase by sector (in \% of total production cost), direct and indirect effects, heavy duty vehicle charge scenario A, selected sectors

intermediate inputs, as derived from the sectorally differentiated results from Sect. 2. Assuming that all production cost increases can be passed on to consumers we arrive at the price changes by sector as denoted in Fig. 3. Price changes are split into direct cost impacts, i.e. cost increases in transporting the sector's own goods and indirect cost impacts, i.e. the result of intermediate inputs in the sector becoming more expensive.

We find that in a number of sectors it is the direct cost impacts that dominate with respect to overall sectoral production cost impact (e.g. in construction or in retail trade). These sectors will clearly try to influence political discussion regarding expanding the scope of the heavy duty vehicle charge (while we assume that price increases can be passed on to consumers, price increases nevertheless reduce overall demand and thus output level, which these sectors will try to avoid). A number of other sectors, however, even though equally strongly affected in terms of overall cost increase, suffer only a small direct cost impact. Here it is the cost increase in intermediate supplies that drives overall production cost increase (indirect cost effect).

Combining these results for production cost changes with the respective shares of products in the standard consumption basket we get the relevant short term impact on the consumer price index, which can be understood as an upper bound. In this way the consumer price rise is restricted to below $0.15 \%$ for rate scenario A (and to 0.50 and $0.08 \%$ for rate scenarios $\mathrm{B}$ and $\mathrm{C}$, respectively). 


\section{Differentiating regional impacts}

Peripheral regions are characterized by a relatively strong dependence on the secondary road network. We may therefore expect that these regions could be more strongly hit by an expansion of the heavy duty vehicle charge to cover the secondary road network. By way of example, we analysed policy impacts on one peripheral region in Austria, the Waldviertel (a north-western region in Lower Austria), and looked at two questions: (1) whether-as a consequence of nationwide expansion of the heavy duty vehicle charge-production costs increase more than the nationwide average, and (2) whether the sectors hit hardest are of particular importance to the region. The region Waldviertel was chosen as it is clearly a peripheral region (far from any significant urban location) for which nevertheless detailed transport data (by goods category, type of trip, road type and distance) is available. Overall, our analysis provided affirmative results for both questions. For most peripheral regions it is not the sectors with largest shares in value added (and in this sense most dominant in economic production) that are the ones hit strongest by this instrument. However, those sectors that are hit strongest are more significant in peripheral regions than in central regions.

Due to data limitations no fully fledged regional input-output tables can be constructed at this small scale level, and thus no regional CGE model and no indirect cost implications can be determined. The procedure used for quantifying regional impact was thus as follows. An initial share of $65 \%$ of freight tonnekilometres (excluding transit) is found on the secondary road network in Waldviertel (with subshares at $68 \%$ for internal transport, $49 \%$ for transport originating, and $63 \%$ for transport with destinations in Waldviertel). The corresponding national figure for Austria is only $42 \%$ (with subshares of 48, 29 and $29 \%$ for the respective categories; Herry et al. 2008). Applying the same procedure as given in Sect. 2.1.1, and adjusting for regional specifics (especially a lower elasticity for modal shift in order to reflect the fewer substitution options available), the respective impacts of charge scenarios A, B and C on transport flows by goods, type of trip and road type are then determined. On combining both the information on the average nationwide sectoral intermediate input structure and on regional specific distances for intermediate freight transport with the transport flows by goods category and with the respective cost changes under the three scenarios, we arrive at the production cost changes by production sector in Waldviertel, and can then compare these to cost changes (following the same procedure) at the national level. With respect to scenario A, the comparison showed that direct production cost impacts are up to $1 \%$ point higher in peripheral regions (e.g. for the sector Stones and Earth production costs rise by $3 \%$ in the peripheral region rather than by $2 \%$ as in the nationwide average). Figure 4 presents the sectoral results.

Second, we find that sectors such as Mining of Stones and Earth, which bear the strongest production cost increase, are over-proportionally relevant in peripheral regions (see Fig. 5). However, in terms of generation of value added, the most important sectors in peripheral regions are relatively lightly affected by the expansion of the heavy duty vehicle charge to the secondary road network (in this case textiles, wood, electrical appliances; all covered under Production and Industry 


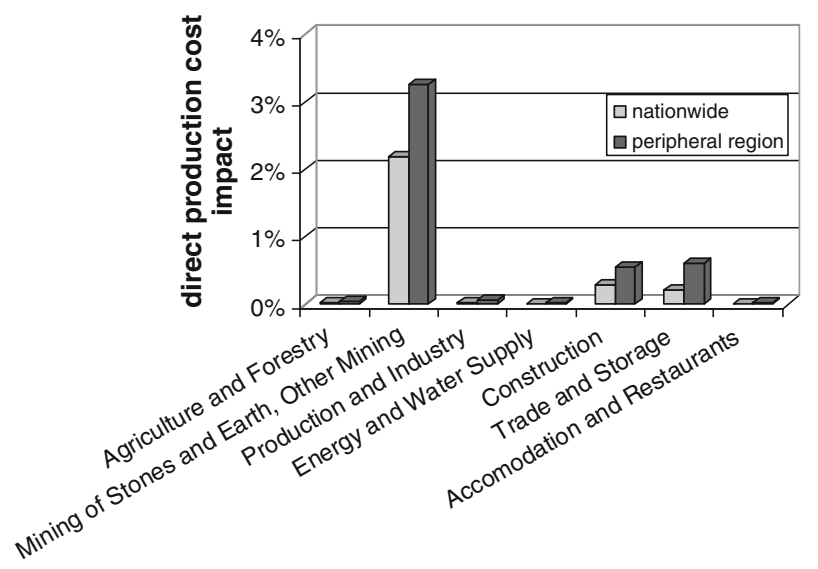

Fig. 4 Direct production cost impact of heavy duty vehicle charge by sector (in \% of total production cost), rate scenario A, peripheral region Waldviertel relative to nationwide

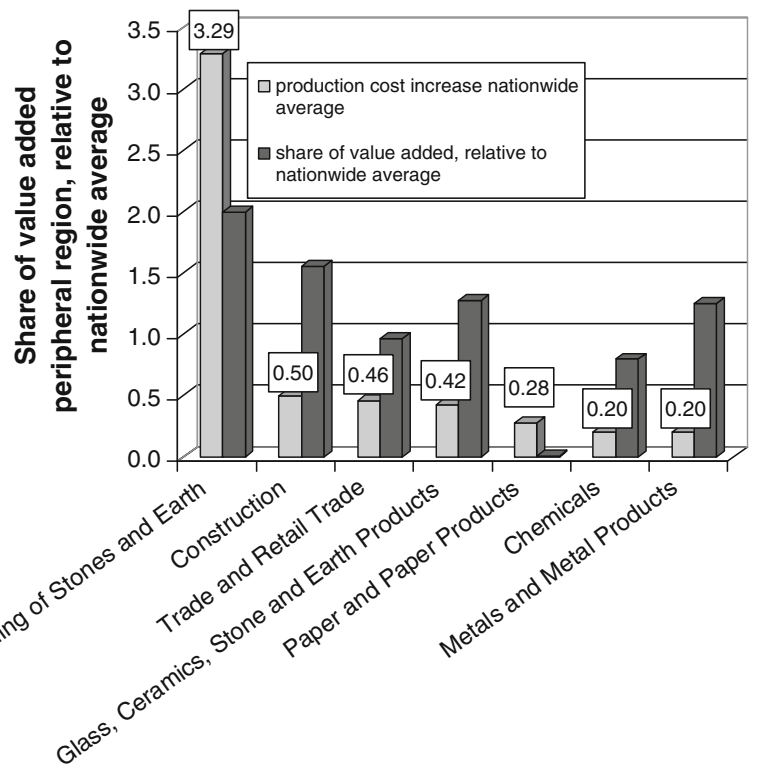

Fig. 5 Relative relevance of sectors that are hit by the heavy duty vehicle charge in peripheral region Waldviertel

in Fig. 4). We thus conclude that while the impact on the peripheral region Waldviertel under tariff scenario $\mathrm{A}$ is disproportionally stronger, the overall significance of the policy remains relatively minor.

In terms of the relative relevance of the secondary road network for a region, the Waldviertel represents an excellent example of a truly peripheral region, with only 
two entry points to the primary road network within its region (both located at a small town at the region's edge), and region-internal transport thus basically fully dependent on the secondary road network. To the extent that other regions have better access to the primary road network, there will be a corresponding decrease in the impact of road transport cost increases compared to that found for the region Waldviertel.

\section{Discussion of results}

Evaluating our results in terms of the sustainable development principles for transport pointed out above in the introduction (Gudmundsson and Höjer 1996), we find the following.

The expansion of the current, primary road network kilometre-based heavy duty vehicle charging system to cover the secondary road network (rate scenario A) does appear to contribute, but not significantly, to the principle of preserving a larger share of natural resources for future generations (thus preserving the capacity of the atmosphere to take up fossil fuel carbon emissions). Freight transport emissions under rate scenario A decline by $1.9 \%$. To achieve a more significant impact we also need a rate increase on the primary road network. In our rate scenario $\mathrm{B}$, for example (doubling charges for both the primary and secondary road network), freight transport emissions decline by $9 \%$.

The policy is thus in accordance with the principle of improving the quality of life for individuals as it entails only a marginal increase in overall production cost (and thus a marginal consumer price increase). It leads to optimization of load factors and routing schedules in freight transport, such that vehicle kilometres (and the related emissions) decline at almost double the rate of tonne-kilometres. Development of the latter can serve as an indicator of consumption product supply, albeit with the provision that reductions in tonne-kilometres do not necessarily translate into reductions of consumer goods supply, as the choice of closer locations of intermediate supply, closer destinations for supply, or of more environmentally friendly modes of transport can have an offsetting effect. Our CGE analysis shows for example, that under rate scenario A, road transport emissions decline by $1.9 \%$, road tonne-kilometres decline by $1 \%$, but private consumption (including shifts to more environmentally benign consumption) declines by only $0.3 \%$.

Expanding the current heavy duty vehicle charge to cover the secondary road network does not comply with the principle of ensuring a fair (here: regional) distribution of life-quality. The resulting economic burdens are clearly stronger in peripheral regions, while the reduction of globally effective emissions benefits all regions equally. However, we could use a different reference point, namely the situation existing before the initial introduction of kilometre based heavy duty vehicle charges. By introducing the charge only for the primary Austrian road network in 2004, the fairness principle with respect to central regions was in fact ignored since the latter are more heavily dependent on the primary road network. Thus, it could be argued that expansion to cover the secondary road network only corrects for this earlier imbalance. 
It is illuminating to structure the discussion of regional fairness along the lines of equality, need, and equity (Hammar and Jagers 2007). The expansion to the secondary road network can be seen to re-establish equality (i.e. establishing equal burdens across regions). Taking as reference point the situation existing before 2004 , i.e. before introducing the charge on the primary road network, charge expansion is also in accordance with the equity principle, as those regions with more emissions should also reduce more. However, it is in conflict with the need principle. Peripheral regions are dependent on longer transport distances. The initial introduction of the heavy duty vehicle charge for the primary road network and an expansion of coverage to the secondary road network in particular, both hit peripheral regions particularly hard, since these face a stronger need for transport services. To ensure that policy conforms to the principle of need, some form of complementary transfer for peripheral regions-not directly linked to the use of freight transport-would need to be implemented. For example, the use of revenues for general tax reduction could be directed towards reducing those non-transport taxes which are of higher relevance for peripheral regions.

In terms of methodology we augment a simple micro-based road freight transport reaction analysis (Herry et al. 2008, as set out in some detail in Sect. 2.1.1 above) by including an economic analysis of market feedbacks at the national scale and of upper bound price (and thus output) effects at the regional scale. The micro-based approach, building upon detailed transport and interview data concerning sectoral freight characteristics enables us to go beyond the usual aggregated economic reaction analysis (denoted usually by elasticities of substitution). On the other hand, by coupling a CGE analysis with this micro-based analysis, we can nevertheless pin down the market-feedbacks at the macro-level which are triggered by individual behaviour, and thus determine ultimate environmental effectiveness and economic implications.

\section{Conclusions}

We develop a methodological framework in this paper in order to analyse the economic and environmental impacts arising from an expansion of the heavy duty vehicle charge system to cover the secondary road network. We define three scenarios for the kilometre based rate in the secondary (and primary) road network. A sectorally detailed micro-based transport analysis of the changes triggered in vehicle- and tonne-kilometres is augmented by an economic analysis.

A nationwide CGE model with a special focus on sectoral freight transport as intermediate input is employed to quantify medium to long term sectoral and overall macroeconomic impacts. We couple the micro-based transport analysis with the CGE model by means of implicit freight transport charges by sector, thus raising the costs of intermediate inputs and triggering direct and indirect (feedback) effects. The model also takes account of the long-term change in the investment structure due to the set up and maintenance of the heavy duty vehicle charging system.

To derive the price implications of such a policy for consumers, even in the short run, we further employed input-output analysis to cover direct and indirect effects. 
Lack of adequate data on economic sectoral interdependence prevented a fully fledged analysis of policy impact in peripheral regions. We therefore combined information on region specific economic output structure (value added by sector) and region specific dependence on the secondary road network for transporting intermediate inputs in order to derive direct production cost impacts for one exemplary peripheral region. We then compared these with the direct production cost impacts at the nationwide level. Finally, we reported on the relative relevance of sectors highly dependent on secondary road freight transport in this typical peripheral region.

The core quantitative results are as follows. For the three scenarios covering expansion of the heavy duty vehicle charge to the secondary road network, the CGE analysis quantifies sectoral shifts in production (here the strongest shift being $-3.5 \%$ in the sector Stones and Earth) and in prices (with the strongest impact being $+2 \%$ in the same sector), as well as in terms of overall economic impacts, particularly on GDP and employment. These macroeconomic impacts depend crucially on the choice of revenue use. The larger the share that is used for general tax relief, the better the macroeconomic implications. When all revenues beyond system costs are spent on tax reductions, and the kilometre charge is high enough, we get net positive employment and GDP effects.

In a pure input-output analysis sectoral price impacts are found to be up to 1.5 times higher than in the CGE analysis. Using the former, we can restrict the shortterm impact on the consumer price index of extending charges to the secondary road network to below $0.15 \%$.

For the typical peripheral region analysed, i.e. Waldviertel, we find that while it is not the sectors of highest economic importance that are hit by the charge, the sectors that are hit are those which are relatively more important in peripheral regions (with up to a twofold share in value added) and simultaneously those which show a stronger production price impact, this latter effect being due to the relative inaccessibility of such regions (more or less by definition) to the primary road network.

In terms of social distribution the direct price effect would appear to imply a slight tendency for poorer households to be over-proportionally hit, as the housing sector is particularly hit by higher construction costs, and as housing expenditure makes up a higher share in consumption for the poor. However, other impacts, especially a change in employment, might be of much higher relevance in terms of distributional implications. Employment effects also depend strongly on revenue use.

In terms of achieving compliance with the core principles of sustainable transport we find that extending charge coverage is largely unproblematic, the one exception here being attaining compatibility with the principle of regional need. However, it appears clear that a significant environmental improvement could only be achieved by a simultaneous increase of the rate for both the primary and secondary road network. Thus, to avoid undermining the needs principle with respect to peripheral regions, the redistribution of revenues should be directed towards those uses which benefit such regions more strongly. This results in our overall policy conclusion that expanding heavy duty vehicle charges to the secondary road network does in fact 
show sufficient positive environmental effects. However, in order to comply with the needs principle, suitable complementary transfer policies need to be designed and implemented for peripheral regions.

Acknowledgment The authors thank Nobert Sedlacek and Max Herry for research cooperation with the micro-based road freight transport reaction model, and two anonymous referees of this journal for their very helpful comments on an earlier version of this paper.

\section{References}

Balmer U (2006) Impact of the heavy vehicle fee in Switzerland. Swiss Federal Office for Spatial Development, Bern

Böhringer C, Löschel A (2006) Computable general equilibrium models for sustainability impact assessment: status quo and prospects. Ecol Econ 60(1):49-64

Bovenberg AL (1999) Green tax reforms and the double dividend: an updated reader's guide. Int Tax Public Financ 6:421-443

Condeco-Melhorade A, Gutiérrez J, García-Palomares JC (2011) Spatial impacts of road pricing: accessibility, regional spill-overs and territorial cohesion. Transp Res Part A 45:185-203

Due Torri (2007) Transport costs in Europe. Bologna: Due Torri SPA, Italy

EC (European Commission) (2001) A sustainable Europe for a better world: a European Union strategy for sustainable development. Commission's Proposal to the Gothenburg European Council, COM (2001)264 Final, Brussels, 15 May 2001

European Council (2011) 'Eurovignette' directive adopted, PRES/11/300, Brussels, 12 Sept 2011 http://register.consilium.euopa.eu/pdf/en/11/pe00/pe00024.en11.pdf

Friedl B, Steininger KW (2002) Environmentally sustainable transport: definition and long-term economic impacts for Austria. Empirica 29:163-180

Grazi F, van den Bergh JCJM (2008) Spatial organization, transport, and climate change: comparing instruments of spatial planning and policy. Ecol Econ 67:630-639

Greene DL (2011) What is greener than a VMT tax? The case for an indexed energy user fee to finance US surface transportation. Transp Res Part D 16:451-458

Gudmundsson H, Hojer M (1996) Sustainable development principles and their implications for transport. Ecol Econ 19:269-282

Hammar $\mathrm{H}$, Jagers SC (2007) What is a fair $\mathrm{CO}_{2}$ tax increase? On fair emission reductions in the transport sector. Ecol Econ 61:377-387

Hao Y-Z, Shao C, Yu L, Song G-H, Xu Y-F (2010) Multi-level analysis of fuel consumption and emissions of heavy-duty diesel vehicles in road network. J Transp Syst Eng Inf Technol 10:123-129

Herry M (2001) Transportkosten und Transportpreise der verschiedenen Verkehrsträger im Güterverkehr. AK Wien, Verkehr und Infrastruktur, Heft 14, Wien

Herry Consult, IWW, NEA, Snizek (2002) Verkehrsplanung: Tarifberechnung fahrleistungsabhängige Maut Österreich und Abschätzung der Verkehrsverlagerung bezüglich der ermittelten Tarife, Wien

Herry Consult (2004) BE-Preisspielräume, im Auftrag von ÖBB. BMVIT und SCHIG, Wien

Herry M, Sedlacek N, Schuster M, Link H, Axhausen H (2001) Österreichische Wegekostenrechnung Straße 2000. Federal Ministry for Transport, Innovation and Technology, Vienna

Herry M, Sedlacek N, Steininger KW, Tobin A (2008) Auswirkungen einer flächendeckenden LKWAbgabe (Unpublished working paper)

ICIPE, Herry M (2001) IMONET - Inter-modales Güterverkehrs-Knoten-Netzwerk Zentraleuropa, Wien

Johnson R (2005) Road wear and the kilometre charge: a computable general equilibrium analysis. J Trans Econ Policy 39:53-74

Kratena K, Meyer I (2011) Energy scenarios 2030. A basis for the projection of Austrian greenhouse gas emissions. Austrian Economic research Institute (WIFO), Vienna

Muller A, Sterner T (eds) (2006) Environmental taxation in practice. Ashgate, Aldershot

Perman R, Ma Y, McGilvray J, Common M (2011) Natural resources and environmental economics, 4th edn. Addison Wesley, Harlow

Reinert KA, Roland-Holst DW (1992) Armington elasticities for United States manufacturing sectors. J Policy Model 14:631-639 
Replogle MA (2008) Is congestion pricing ready for prime time? Planning 74:6-11

Statistik Austria (2002) Verbrauchsausgaben 1999/2000. Sozialstatistische Ergebnisse der Konsumerhebung, Vienna

Steininger KW (2002) The foreign trade and sectoral impact of truck road pricing for cross-border trade: a CGE analysis for a small open economy. Environ Resource Econ 23:213-253

Takeshita T (2011) Global scenarios of air pollutant emissions from road transport through 2050. Int J Environ Res Public Health 8:3032-3062

Törnblom KY, Foa UG (1983) Choice of a distribution principle: cross cultural evidence on the effects of resources. Acta Sociologica 26:161-173

Veen-Groot DB, Nijkamp P (1999) Globalisation, transport and the environment: new perspectives for ecological economics. Ecol Econ 31:331-346

Yang C, McCollum D, McCarthy R, Leighty W (2009) Meeting an 80\% reduction in greenhouse gas emissions from transportation by 2050: a case study in California. Transp Res Part D 14:147-156 